\title{
Delayed Surgery for Rectal Cancer Patients Receiving Neoadjuvant Chemoradiotherapy: A Promising Method in Its Infancy
}

\author{
Jia-Yuan Peng Jian-Zhong Di Yu Wang \\ Department of Surgery, The Sixth People's Hospital, Shanghai Jiao Tong University, Shanghai, China
}

\author{
Key Words \\ Delayed surgery $\cdot$ Rectal cancer · Neoadjuvant \\ chemoradiotherapy
}

\begin{abstract}
Background: Neoadjuvant chemoradiotherapy (nCRT) is used to downstage locally advanced rectal cancer before surgery. Accumulating data suggest that tumor response to $\mathrm{nCRT}$ is time dependent. A delay between $\mathrm{nCRT}$ and surgery may increase the proportion of patients that achieve a favorable response. However, delayed surgery beyond 6-8 weeks may increase the technical difficulty, and the risks of surgical complications and recurrence or metastasis. This article briefly reviews the relevant literature to evaluate the efficiency and safety of delayed surgery. Methods: Two noncohort studies and 10 cohort studies were reviewed. The results were analyzed and the limitations discussed. Results: Although debatable, the findings of the included studies are promising. Delayed surgery may increase the proportion of favorable tumor response without compromising prognosis. However, most of the studies were retrospective, which introduces bias into the evaluation. Conclusion: Delayed surgery is potentially useful, but this needs to be verified by further well-designed prospective trials.
\end{abstract}

Copyright @ 2012 S. Karger AG, Basel

\section{Introduction}

The two main goals in the treatment of advanced rectal cancer are R0 resection of tumor and increasing the possibility of sphincter preservation. For locally progressive cancers, neoadjuvant chemoradiotherapy (nCRT) can induce tumor regression and thereby facilitate subsequent resection, resulting in improved local control and survival $[1,2]$. The traditional time interval between nCRT and surgery is often within 6 weeks [3-7], which is considered to improve tumor response and allow patients to recover adequately from any toxicity of the nCRT. However, research has suggested that a greater pathological remission rate could be achieved if surgical resection is further delayed [8-10]. This time-dependent response has promoted some authors to prolong the interval between nCRT and surgery, expecting a greater proportion of patients to undergo radical resection $[11,12]$. Here, we present a short review of recent research regarding delayed surgery to offer an objective evaluation.

\section{Implications from Non-Cohort Research}

The concept of delayed surgery may derive from the implications of certain non-cohort studies in which

J.-Y.P. and J.-Z.D. contributed equally to this work.

\section{KARGER \\ Fax +4161306 1234 \\ E-Mail karger@karger.ch}

www.karger.com
(C) 2012 S. Karger AG, Basel

0253-4886/12/0294-0281\$38.00/0

Accessible online at: www.karger.com/dsu
Yu Wang

Department of Surgery, The Sixth People's Hospital

Shanghai Jiao Tong University

600 Yishan Road

Shanghai 200233 (China)

Tel. +86 216436 1349, E-Mail wangyu11122@yahoo.cn 
patients received radiotherapy as the primary treatment due to their general physical condition or the presence of advanced cancer. According to time-response curves, in patients who achieved a clinical complete response, $50 \%$ had reached their maximal response by 4 months after the start of radiotherapy (equivalent to a 10-week interval), while $30-40 \%$ achieved complete response as late as 5-8 months $[13,14]$. Two recent retrospective studies reviewed data from selected patients receiving short-course preoperative radiotherapy $(5 \times 5$ Gy $)$ with delayed surgery (6-8 weeks later) $[15,16]$. The reasons for this regimen included advanced age, presence of comorbidities and nonresectable cancers. The regimen proved to be efficient and well tolerated. The curative resection $(\mathrm{R} 0+\mathrm{R} 1)$ rates in the two studies were as high as $58.5 \%$ (24 of 41 patients) and 69.6\% (32 of 46 patients) due to tumor downstaging. The two most common reported complications were diarrhea $[15,16]$, which was most often observed in patients above 80 years of age, and infection, including wound and pelvic infection [16]. Radiotherapy-related side effects such as colovaginal fistula and radiation-induced enteritis were recorded in individual cases [16]. Based on the above findings, it was suggested that a longer interval between preoperative radiotherapy and surgery may permit ongoing tumor apoptosis, whereas surgery before this time can disturb this process, allowing viable cancer cells to survive.

\section{Results from Cohort Studies}

\section{Tumor Remission}

To better understand the influence of delayed surgery, cohort studies were conducted. The first randomized trial, Lyon R90-01, was conducted in 1999 [17]. It was found that a 6- to 8-week interval could improve tumor downstaging rates compared with an interval of 2 weeks, without significantly improving the sphincter preservation rate and local control. Enlightened by the results of Lyon R90-01, subsequent investigations [9, 12, 18-22] went further and some even prolonged the interval from 8 weeks to $>12$ weeks $[19,20]$. The main reason for this extension was the integration of 5-fluorouracil-based chemotherapy into preoperative treatments. 5-Fluorouracil and radiotherapy were reported to each enhance the efficacy of the other $[23,24]$, and it was therefore expected that surgeons would have to 'wait' longer. Overall, of the 10 relevant cohort studies reviewed, 6 found that a longer interval translated to a greater proportion of patients experiencing tumor remission $[9,12,17,18,20$,
25] (table 1). Interestingly, the downstaging impact was more significant with respect to tumor volume than the number of involved lymph nodes [12, 17, 18, 25]. The other four studies found no significant improvements in cancer regression $[10,19,22,26]$ (table 1).

This inconsistency has complex causes. First, in three studies with negative results, the comparison between two cohorts was conducted by simply defining a certain time such as 44 days [10], 6 weeks [26] or 8 weeks [22]. However, this may not have accurately reflected a trend of increasing response rate with increased interval, because tumor necrosis is an ongoing process. In contrast, in the studies with positive findings, most compared effects by defining two or more different periods of time (e.g. a 2-week interval vs. a 6- to 8 -week interval) [12, $17,18,25]$. This may be the reason why a trend was apparent in one study with negative results ( $9 \%$ with a 30 to 40 -day interval vs. $23 \%$ with $>49$ days) [10]. Second, the sample size might be important. In all of the relevant studies included in the present review, one found a higher response rate in the shorter interval group, but only 33 patients were enrolled [19]. Two of the four studies with negative results also had relatively small samples $[19,22]$. In comparison, the sample size ranged from 107 to 210 patients in the studies with positive results $[9,12,17,18$, 20]. Third, the regimen used, especially that for chemotherapy, may have an influence. Two studies showed that oxaliplatin plus 5-fluorouracil achieved a higher pathological complete remission rate than 5-fluorouracil alone $[12,18]$. Notably, in three studies, no tumor response was apparent when irinotecan was added [10, 19, 26], though this issue was not further explored by stratified analysis. Some randomized phase III trials have shown that addition of irinotecan to leucovorin +5 -fluorouracil (LV5FU2) as adjuvant therapy did not confer a statistically significant improvement in disease-free survival (DFS) or overall survival in patients with advanced colon cancer compared with LV5FU2 alone [27, 28]. Although no evidence can prove that irinotecan is less efficient in neoadjuvant chemotherapy, this does remind us that a combination of two agents does not necessarily equate to an intensified tumor-killing effect.

Based on the current literature, we can draw a primary conclusion that an interval of no less than $8-12$ weeks is more effective than a shorter interval (within 4-6 weeks) regarding preoperative downsizing of rectal cancer. However, some uncertainties remain. Will extension beyond 12 weeks bring more benefits? A certain proportion of patients are not sensitive to nCRT regardless of the duration of the interval. How can we identify potential 
Table 1. Cohort studies of the relationship between interval and tumor response

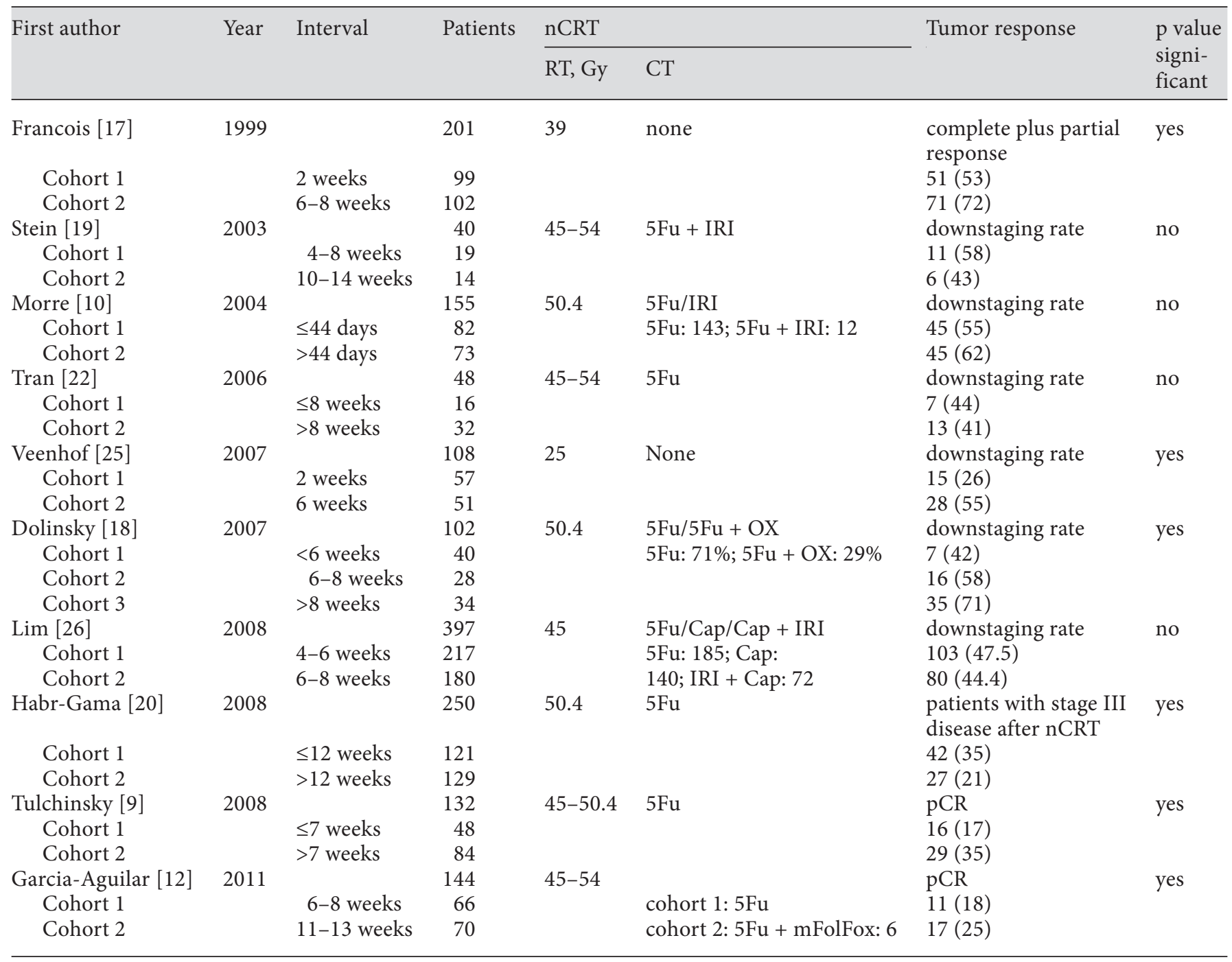

Figures in parentheses indicate percentages. $5 \mathrm{Fu}=5$-Fluorouracil; $\mathrm{OX}=$ oxaliplatin; $\mathrm{IRI}=$ irinotecan; Cap $=$ capecitabine; $\mathrm{pCR}=$ pathological complete remission; CT = chemotherapy; RT = radiotherapy.

responders? What effect would a more intense regimen (chemotherapy containing 5-fluorouracil plus oxaliplatin or irinotecan) have on the optimal interval? We need more prospective and well-designed randomized trials with uniform regimens, definition of tumor response and choice of interval to investigate these vital issues.

\section{Effect on Prognosis}

In dissected specimens from patients receiving nCRT, isolated cancer deposits, known as tumor buds or mesorectal microfoci, are more commonly detected and have an adverse impact on prognosis [29-32]. The growth rate of residual deposits would be accelerated if the overall time from surgery to completion of radiotherapy was protracted [33], and concerns have been raised about whether a longer interval before surgery might result in recovery or in proliferation and spread of tumor deposits. However, in most studies with data on prognosis [11, $17,21,26,34]$, DFS was not compromised by delayed surgery within 12 weeks. Furthermore, in the study of Tulchinsky et al. [9], DFS was better in the longer interval group. Thus, this concern is questionable. A series of 
previous studies has demonstrated that favorable tumor response is correlated with improved local control and survival $[1-4,6,7,29]$.

Given the comparable or better tumor response achieved with a prolonged interval, delayed surgery is not thought to result in higher rates of local relapse and distant metastasis. Nevertheless, two issues warrant attention. First, it is unknown whether the prognosis would be better than or comparable with that seen at present if the duration of the current longer intervals was further extended. Some investigators found that a too long interval (>12-16 weeks) between diagnosis and surgery was associated with poor DFS $[34,35]$. Will it be the same case when the 'interval' refers to the time between the initiation of neoadjuvant therapy and surgery? Second, the average follow-up time in the present studies was $\leq 5$ years, but nCRT has been reported to have a chronic impact on the natural history of rectal cancer in some patients, leading to delayed recurrence $[8,36,37]$. The follow-up period in the current studies might therefore not be long enough and may need to be extended for accurate evaluation.

\section{Morbidity and Mortality}

The influence of a prolonged interval on surgical difficulty, postoperative morbidity and mortality is a vital consideration. Waiting too long may lead to excessive fibrosis [12] that adds to the difficulty of resection. Tran et al. [22] found that operative time was relatively longer following an interval of $>8$ weeks compared with a shorter interval ( $\leq 8$ weeks; 280 vs. $210 \mathrm{~min}, \mathrm{p}=0.05$ ). Considering the similarity of surgical procedures, the longer operative time may to some extent be due to the longer interval. The average duration of hospital stay was also extended in longer interval group (7.7 vs. 9.9 days, $\mathrm{p}=0.02)$. However, these findings were not repeated in other studies $[9,10,12,17,19,25,26,34]$, which did not observe any significant increase in mortality or morbidity, including intraoperative blood loss, infection and anastomosis complications. Furthermore, a longer interval may allow patients to recover from nCRT-related toxicity. A longer interval may therefore be regarded as safe based on current data. However, factors other than the interval can affect morbidity and mortality, and further multivariable analysis is needed to verify the current results.

\section{Discussion}

The optimal timing of surgery after neoadjuvant therapy has been poorly studied in recent decades. The interval in the studies was usually approximately 4-6 weeks $[3,29,38,39]$. The reported tumor remission rate was approximately $40-60 \%$, and favorable response may translate to potential $\mathrm{R} 0$ resectability. In most cases, the choice of interval is based on the surgeon's personal experience or preference. With time, however, a further proportion of patients might be identified as 'responders' and subsequently undergo radical surgery. In rare cases, randomized prospective trials have been established to explore the appropriate interval in the context of different preoperative regimens. Data from retrospective studies are promising but bias is inevitable. For instance, patients might choose to have their surgery delayed, or surgeons may wait longer for patients with bulky cancers. This leads to a wide range of intervals to be analyzed. In addition, the inconsistency of regimens between cohorts $[10,12,18,26]$ may add to the complexity of the analysis. Information from most prospective studies of neoadjuvant treatment is limited because determining the optimal interval was not the major goal. In the next 5 years, well-designed randomized control trials are needed. These trials should compare different ranges of intervals and investigate the influence of different preoperative regimens. Accurate time-response curves will be required to clarify the exact duration of a 'longer interval'. The specific mechanism involved may also be elucidated by animal or cell experiments.

\section{Acknowledgement}

We thank Prof. Qi Zheng for his constructive advice on this review.

\section{Disclosure Statement}

None. 


\section{References}

1 Garcia-Aguilar J, Hernandez de Anda E, Sirivongs $\mathrm{P}$, Lee $\mathrm{SH}$, Madoff $\mathrm{RD}$, Rothenberger DA: A pathologic complete response to preoperative chemoradiation is associated with lower local recurrence and improved survival in rectal cancer patients treated by mesorectal excision. Dis Colon Rectum 2003;46: 298-304.

2 Maas M, Nelemans PJ, Valentini V, Das P, Rodel C, Kuo LJ, Calvo FA, Garcia-Aguilar J, Glynne-Jones R, Haustermans K, Mohiuddin M, Pucciarelli S, Small W Jr, Suarez J, Theodoropoulos G, Biondo S, Beets-Tan RG, Beets GL: Long-term outcome in patients with a pathological complete response after chemoradiation for rectal cancer: a pooled analysis of individual patient data. Lancet Oncol 2010;11:835-844.

-3 Hughes R, Glynne-Jones R, Grainger J, Richman P, Makris A, Harrison M, Ashford R, Harrison RA, Livingstone JI, McDonald PJ, Meyrick Thomas J, Mitchell IC, Northover JM, Phillips R, Wallace M, Windsor A, Novell JR: Can pathological complete response in the primary tumour following pre-operative pelvic chemoradiotherapy for T3-T4 rectal cancer predict for sterilisation of pelvic lymph nodes, a low risk of local recurrence and the appropriateness of local excision? Int J Colorectal Dis 2006;21:11-17.

4 Kim NK, Baik SH, Seong JS, Kim H, Roh JK, Lee KY, Sohn SK, Cho CH: Oncologic outcomes after neoadjuvant chemoradiation followed by curative resection with tumorspecific mesorectal excision for fixed locally advanced rectal cancer: impact of postirradiated pathologic downstaging on local recurrence and survival. Ann Surg 2006;244: 1024-1030.

5 Lim YK, Law WL, Liu R, Poon JT, Fan JF, Lo OS: Impact of neoadjuvant treatment on total mesorectal excision for ultra-low rectal cancers. World J Surg Oncol 2010;8:23.

-6 Stipa F, Chessin DB, Shia J, Paty PB, Weiser M, Temple LK, Minsky BD, Wong WD, Guillem JG: A pathologic complete response of rectal cancer to preoperative combinedmodality therapy results in improved oncological outcome compared with those who achieve no downstaging on the basis of preoperative endorectal ultrasonography. Ann Surg Oncol 2006;13:1047-1053.

7 Topova L, Hellmich G, Puffer E, Schubert C, Christen N, Boldt T, Wiedemann B, Witzigmann H, Stelzner S: Prognostic value of tumor response to neoadjuvant therapy in rectal carcinoma. Dis Colon Rectum 2011;54: 401-411.
8 Habr-Gama A, Perez RO, Proscurshim I, Campos FG, Nadalin W, Kiss D, Gama-Rodrigues J: Patterns of failure and survival for nonoperative treatment of stage $\mathrm{c} 0$ distal rectal cancer following neoadjuvant chemoradiation therapy. J Gastrointest Surg 2006;10: 1319-1328; discussion 1328-1319.

-9 Tulchinsky H, Shmueli E, Figer A, Klausner JM, Rabau M: An interval $>7$ weeks between neoadjuvant therapy and surgery improves pathologic complete response and diseasefree survival in patients with locally advanced rectal cancer. Ann Surg Oncol 2008;15: 2661-2667.

10 Moore HG, Gittleman AE, Minsky BD, Wong D, Paty PB, Weiser M, Temple L, Saltz L, Shia J, Guillem JG: Rate of pathologic complete response with increased interval between preoperative combined modality therapy and rectal cancer resection. Dis Colon Rectum 2004;47:279-286.

11 Glehen O, Chapet O, Adham M, Nemoz JC, Gerard JP: Long-term results of the Lyons R90-01 randomized trial of preoperative radiotherapy with delayed surgery and its effect on sphincter-saving surgery in rectal cancer. Br J Surg 2003;90:996-998.

12 Garcia-Aguilar J, Smith DD, Avila K, Bergsland EK, Chu P, Krieg RM: Optimal timing of surgery after chemoradiation for advanced rectal cancer: preliminary results of a multicenter, nonrandomized phase II prospective trial. Ann Surg 2011;254:97-102.

13 Wang Y, Cummings B, Catton P, Dawson L, Kim J, Ringash J, Wong R, Yi QL, Brierley J: Primary radical external beam radiotherapy of rectal adenocarcinoma: long term outcome of 271 patients. Radiother Oncol 2005; 77:126-132.

14 Brierley JD, Cummings BJ, Wong CS, Keane TJ, O'Sullivan B, Catton CN, Goodman P: Adenocarcinoma of the rectum treated by radical external radiation therapy. Int $J$ Radiat Oncol Biol Phys 1995;31:255-259.

15 Radu C, Berglund A, Pahlman L, Glimelius B: Short-course preoperative radiotherapy with delayed surgery in rectal cancer - a retrospective study. Radiother Oncol 2008;87: 343-349.

16 Hatfield P, Hingorani M, Radhakrishna G, Cooper R, Melcher A, Crellin A, Kwok-Williams M, Sebag-Montefiore D: Short-course radiotherapy, with elective delay prior to surgery, in patients with unresectable rectal cancer who have poor performance status or significant co-morbidity. Radiother Oncol 2009;92:210-214.

17 Francois Y, Nemoz CJ, Baulieux J, Vignal J, Grandjean JP, Partensky C, Souquet JC, Adeleine P, Gerard JP: Influence of the interval between preoperative radiation therapy and surgery on downstaging and on the rate of sphincter-sparing surgery for rectal cancer: the Lyon R90-01 randomized trial. J Clin Oncol 1999;17:2396.
18 Dolinsky CM, Mahmoud NN, Mick R, Sun W, Whittington RW, Solin LJ, Haller DG, Giantonio BJ, O’Dwyer PJ, Rosato EF, Fry RD, Metz JM: Effect of time interval between surgery and preoperative chemoradiotherapy with 5-fluorouracil or 5-fluorouracil and oxaliplatin on outcomes in rectal cancer. J Surg Oncol 2007;96:207-212.

19 Stein DE, Mahmoud NN, Anne PR, Rose DG, Isenberg GA, Goldstein SD, Mitchell E, Fry RD: Longer time interval between completion of neoadjuvant chemoradiation and surgical resection does not improve downstaging of rectal carcinoma. Dis Colon Rectum 2003;46:448-453.

20 Habr-Gama A, Perez RO, Proscurshim I, Nunes Dos Santos RM, Kiss D, Gama-Rodrigues J, Cecconello I: Interval between surgery and neoadjuvant chemoradiation therapy for distal rectal cancer: does delayed surgery have an impact on outcome? Int J Radiat Oncol Biol Phys 2008;71:1181-1188.

21 Kerr SF, Norton S, Glynne-Jones R: Delaying surgery after neoadjuvant chemoradiotherapy for rectal cancer may reduce postoperative morbidity without compromising prognosis. Br J Surg 2008;95:1534-1540.

22 Tran CL, Udani S, Holt A, Arnell T, Kumar R, Stamos MJ: Evaluation of safety of increased time interval between chemoradiation and resection for rectal cancer. Am J Surg 2006; 192:873-877.

23 Crane CH, Skibber JM, Birnbaum EH, Feig BW, Singh AK, Delclos ME, Lin EH, Fleshman JW, Thames HD, Kodner IJ, Lockett MA, Picus J, Phan T, Chandra A, Janjan NA, Read TE, Myerson RJ: The addition of continuous infusion 5-FU to preoperative radiation therapy increases tumor response, leading to increased sphincter preservation in locally advanced rectal cancer. Int J Radiat Oncol Biol Phys 2003;57:84-89.

24 Sawada N, Ishikawa T, Sekiguchi F, Tanaka Y, Ishitsuka H: X-ray irradiation induces thymidine phosphorylase and enhances the efficacy of capecitabine (Xeloda) in human cancer xenografts. Clin Cancer Res 1999;5: 2948-2953.

-25 Veenhof AA, Kropman RH, Engel AF, Craanen ME, Meijer S, Meijer OW, van der Peet DL, Cuesta MA: Preoperative radiation therapy for locally advanced rectal cancer: a comparison between two different time intervals to surgery. Int J Colorectal Dis 2007; 22:507-513.

26 Lim SB, Choi HS, Jeong SY, Kim DY, Jung KH, Hong YS, Chang HJ, Park JG: Optimal surgery time after preoperative chemoradiotherapy for locally advanced rectal cancers. Ann Surg 2008;248:243-251. 
27 Van Cutsem E, Labianca R, Bodoky G, Barone C, Aranda E, Nordlinger B, Topham C, Tabernero J, Andre T, Sobrero AF, Mini E, Greil R, Di Costanzo F, Collette L, Cisar L, Zhang X, Khayat D, Bokemeyer C, Roth $\mathrm{AD}$, Cunningham D: Randomized phase III trial comparing biweekly infusional fluorouracil/leucovorin alone or with irinotecan in the adjuvant treatment of stage III colon cancer: PETACC-3. J Clin Oncol 2009;27: 3117-3125.

-28 Ychou M, Raoul JL, Douillard JY, GourgouBourgade S, Bugat R, Mineur L, Viret F, Becouarn Y, Bouche O, Gamelin E, Ducreux M, Conroy T, Seitz JF, Bedenne L, Kramar A: A phase III randomised trial of LV5FU2 + irinotecan versus LV5FU2 alone in adjuvant high-risk colon cancer (FNCLCC Accord02/FFCD9802). Ann Oncol 2009;20: 674-680.

29 Gavioli M, Luppi G, Losi L, Bertolini F, Santantonio M, Falchi AM, D’Amico R, Conte PF, Natalini G: Incidence and clinical impact of sterilized disease and minimal residual disease after preoperative radiochemotherapy for rectal cancer. Dis Colon Rectum 2005; 48:1851-1857.
30 Rubio CA: Arrest of cell proliferation in budding tumor cells ahead of the invading edge of colonic carcinomas. A preliminary report. Anticancer Res 2008;28:2417-2420.

31 Ratto C, Ricci R, Valentini V, Castri F, Parello A, Gambacorta MA, Cellini N, Vecchio FM, Doglietto GB: Neoplastic mesorectal microfoci (MMF) following neoadjuvant chemoradiotherapy: clinical and prognostic implications. Ann Surg Oncol 2007;14: 853-861.

32 Ratto C, Ricci R, Rossi C, Morelli U, Vecchio FM, Doglietto GB: Mesorectal microfoci adversely affect the prognosis of patients with rectal cancer. Dis Colon Rectum 2002;45: 733-742, discussion 742-733.

33 Suwinski R, Taylor JM, Withers HR: Rapid growth of microscopic rectal cancer as a determinant of response to preoperative radiation therapy. Int J Radiat Oncol Biol Phys 1998;42:943-951.

34 Supiot S, Bennouna J, Rio E, Meurette G, Bardet E, Buecher B, Dravet F, Le Neel JC, Douillard JY, Mahe MA, Lehur PA: Negative influence of delayed surgery on survival after preoperative radiotherapy in rectal cancer. Colorectal Dis 2006;8:430-435.
35 Richards MA, Smith P, Ramirez AJ, Fentiman IS, Rubens RD: The influence on survival of delay in the presentation and treatment of symptomatic breast cancer. $\mathrm{Br} J$ Cancer 1999;79:858-864.

36 Kusters M, Velde CJH, Beets-Tan RGH, Akasu T, Fujida S, Yamamoto S, Moriya Y: Patterns of local recurrence in rectal cancer: a single-center experience. Ann Surg Oncol 2008;16:289-296.

37 Ahmad NR, Nagle D: Long-term results of preoperative radiation therapy alone for stage T3 and T4 rectal cancer. Br J Surg 1997; 84:1445-1448.

38 Zmora O, Dasilva GM, Gurland B, Pfeffer R, Koller M, Nogueras JJ, Wexner SD: Does rectal wall tumor eradication with preoperative chemoradiation permit a change in the operative strategy? Dis Colon Rectum 2004; 47:1607-1612.

-39 Bujko K, Nowacki MP, Nasierowska-Guttmejer A, Kepka L, Winkler-Spytkowska B, Suwinski R, Oledzki J, Stryczynska G, Wieczorek A, Serkies K, Rogowska D, Tokar P: Prediction of mesorectal nodal metastases after chemoradiation for rectal cancer: results of a randomised trial: implication for subsequent local excision. Radiother Oncol 2005;76:234-240. 